\title{
О КЛИНИКО - ПАТОЛОГОАНАТОМИЧЕСКИХ АСПЕКТАХ ИНТЕРПРЕТАЦИИ ДАННЫХ ОЦЕНКИ КАЧЕСТВА МЕДИЦИНСКОЙ ПОМОЩИ ПРИ ОСТРОМ ЖИВОТЕ В СЛУЧАЯХ КОНСТАТАЦИИ СОСТОЯНИЯ COVID - 19 (НА МОДЕЛИ ПЕРФОРАТИВНОЙ ЯЗВЫ ДВЕНАДЦАТИПЕРСНОЙ КИШКИ)
}

\section{ABOUT CLINICAL AND PATHOLOGICAL ASPECTS IN INTERPRETATION OF ESTIMATED DATA OF MEDICAL CARE QUALITY IN ACUTE ABDOMINAL INJURY STATE IN CASES OF COVID-19 IDENTIFICATION (BASED ON MODEL OF DUODENAL ULCER PERFORATION)}

\section{Movchan \\ V. Tatarkin \\ M. Darina \\ D. Tvorogov \\ K. Chernov \\ A. Zharkov \\ B. Artyushin \\ A. Povaliy}

Summary. Coronavirus disease usually affects people with metabolism disorders, oncological state, chronic diseases of respiratory system, cardiovascular system and gastrointestinal system. In Saint-Petersburg, in period from March to August 2020 there were discussed 803 lethal cases of people, who have been affected by COVID-19 and died. Separately, the data of 60 surgical diseases was examined. Case of patient with perforated duodenal ulcer and COVID-19 state is discussed in this article. It was found, that in case of coronavirus disease the main role in tanatogenesis plays not only the severe course of disease, but also complications of disease that patients already have (also duodenal ulcers, in particular - perforation). The last one is need to be taken into account via interpretation of data of pathological examination via expertise the medical care quality in cases of perforated duodenal ulcer with COVID-19 state. Difficulties in estimation the root-cause connexion of disease course with lethal exodus are undoubted. Certainly, in severe (not simple) cases of acute abdominal state, the collegial discussion is preferred and should not be as similar as a trial.

Keywords: safety of medical activity, quality of surgical care, acute surgical diseases of abdominal organs, perforated gastroduodenal ulcers, COVID-19, management in urgent abdominal surgery.
Мовчан Константин Николаевич

Д.м.н., професссор, СПб ГБУЗ «Медицинский информационно-аналитический центр»; ФГБОУ ВО

«Северо-Западный государственный медицинский университет имени И. И. Мечникова» Минздрава России movchank@miac.zdrav.spb.ru

Татаркин Владислав Владимирович

Старший преподаватель, ФГБОУ ВО «СевероЗападный государственный медицинский университет имени И. И. Мечникова» Минздрава России vlad1k2@yandex.ru

Дарьина Мария Геннадьевна

К.м.н., СПб ГБУз «Медицинский информачионноаналитический чентр»; дочент, ФГБОУ ВО «СевероЗападный государственный медицинский университет имени И. И. Мечникова» Минздрава России

DaryinaM@spbmiac.ru

Творогов Дмитрий Анатольевич

К.м.н., дочент, ФГБОУВО «Северо-Западный государственный медицинский университет имени И. И. Мечникова» Минздрава России tvorogovd@bk.ru

Чернов Кирилл Евгеньевич

К.м.н., эксперт, СПб ГБУЗ «Медицинский информачионно-аналитический чентр»

Жарков Александр Вячеславович

К.м.н., эксперт, СПб ГБУЗ «Медицинский информачионно-аналитический чентр»

Артюшин Борис Сергеевич

К.м.н., дочент, врач-методист, СПб ГБУз

«Медицинский информационно-аналитический чентр»

Повалий Андрей Александрович

Эксперт, СПб ГБУз «Медицинский информационноаналитический центр»

Аннотация. Инфицированию короновирусом чаще подвержены люди с сопутствующей патологией обмена веществ, онкопроцессами, хроническими заболеваниями органов дыхания, сердечно-сосудистой и пищеварительной систем. В Санкт-Петербурге с марта по август 2020 г. коллегиально разобраны 803 случая летальных исходов у людей, умерших на фоне констатации факта их инфицированности COVID-19. Отдельно изучены данные 0 60 наблюдениях хирургических заболеваний. Данные о случае сочетания перфоративной дуоденальной язвы и COVID-19 отражены в содержании пу- 


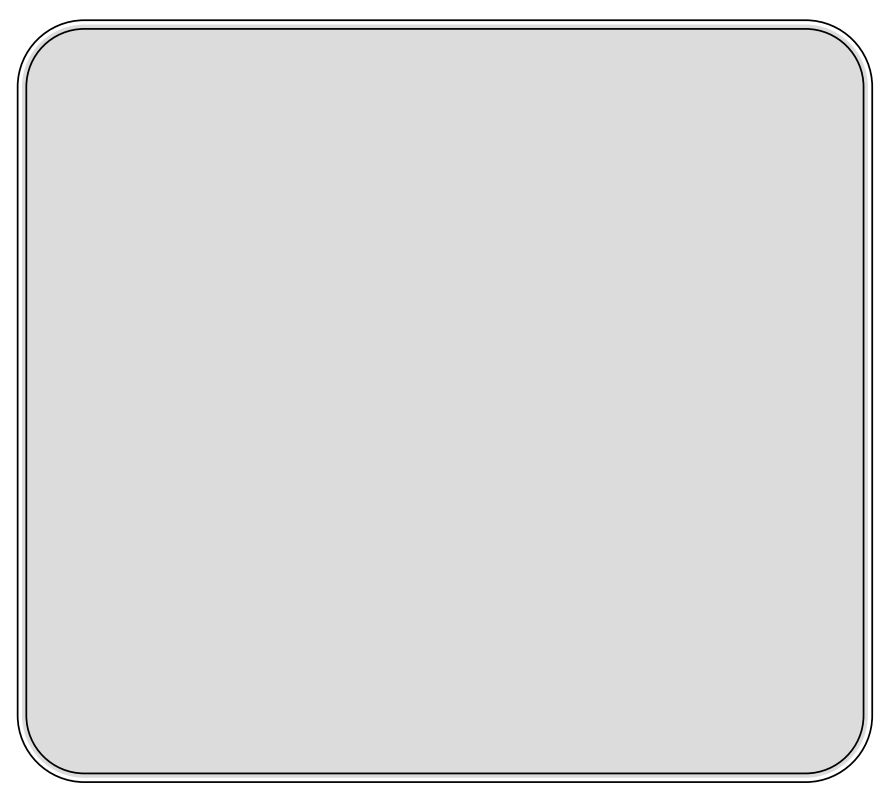

\section{Актуа^ьность}

B ысокие показатели заболеваемости населения новой коронавирусной инфекцией - НКВИ (COVID-19, SARS-Cov-2) сохраняются во многих странах мира, обусловливая существенные негативные последствия в экономике государств [10, 18]. Изменения в социально значимых сферах жизни людей на фоне пандемии COVID-19 обрели глобальный масштаб $[24,35]$. В России в начале августа 2020 г. зарегистрированы более чем 850 тыс. случаев инфицирования людей вирусом SARS-CoV-2 [31]. Энергичные научно-обоснованные действия уполномоченных представителей исполнительных органов государственной власти, направленные на соблюдение мер профилактики COVID-19, а также строгий контроль за своевременным выявлением случаев этого заболевания продолжаются $[5,18,30]$. Однако количество наблюдений SARS-CoV-2 в ряде регионов страны не уменьшается, а в некоторых субъектах РФ даже увеличивается $[2,7,11,14,25]$.

Население мира подвергается инфицированию COVID-19 нередко уже находясь под целенаправленным медицинским наблюдением в связи с хронической сопутствующей патологией, в частности: - сахарным диабетом, хроническими заболеваниями органов дыхания, сердечно-сосудистой и других систем организма, онкозаболеваниями, болезнями органов пищеварения $[8,12$, $17,20,41,43,48,52]$.

Особую группу риска по инфицированию COVID-19 составляют пациенты с онкопатологией $[8,13,26,39,40$, $47,49]$. Некоторые частные формы заболеваний представляются Топ-овыми в рейтинге значимости по танатогенезу в случаях летальных исходов, констатируемых бликации особо. Отмечено, что на фоне инфицированности короновирусом основную роль в танатогенезе играет не только тяжелое течение специфической пневмонии, но и осложнения сопутствующей патологии (В том числе язв двенадцатиперстной кишки, в частности, 一 их прободения). Последнее необходимо учитывать при интерпритации данных патолоанатомического исследования при экспертизе качества медицинской помощи в случаях перфоративной дуоденальной язвы, сочетанной с состоянием новой короновирусной инфекции. Сложности оценки установления причинно-следственной Связи течения соматического заболевания с летальным исходом от COVID 19 инфецирования. Безусловно, в не стандартных случаях «острого живота», В таких как их сочетание с короновирусной инфекцией, коллегиальное обсуждение профессиональным сообществом предпочтительно и не должно уподобляться разбирательству в подразделениях следственных инстанций.

Ключевые слова: безопасность медицинской деятельности, качество хирургической помощи, острые хирургические заболевания органов живота, перфоративные гастродуоденальные язвы, COVID — 19, менеджмент в неотложной абдоминальной хирургии.

при сочетании хронического заболевания органов пищеварения и COVID-19. В этом отношении не составляет исключения и язвенная болезнь желудка и двенадцатиперстной кишки [4, 23, 27, 38, 29, 45, 46, 51].

Одним из нередких острых хирургических заболеваний органов брюшной полости (ОХЗОБП) считается прободение гастродуоденальных язв - ПерфГдя [3, 4, 9, 22, $23,32,42,44]$. Оно сопряжено со сложностью диагностики т.к. данное патологическое состояние характеризуется многообразием манифестных форм и представляет фатальное осложнение язвенной болезни [4, 50]. О6следование и лечение больных перитонитом на почве ПерфГдя может сопровождаться ошибками диагностики с принятием нерациональных тактических решений оказания медицинской помощи - МП [4, 6, 15, 21, 36]. Особенно часто случаи смерти констатируются у больных ПерфГДЯ с выраженным коморбидным статусом [3, 6]. Так происходит и в случаях ПерфГДЯ на фоне тяжелой сопутствующей патологии инфекционного генеза. В настоящее время, когда медицинским работникам приходится оказывать помощь пациентам в условиях пандемии COVID-19, могут возникать сложности в вопросах интерпретации данных оценки КМП при ПерфГДЯ в случаях констатации факта пребывания больных в состоянии новой короновирусной инфекции. Данные обстоятельства оказываются основанием для специального изучения критериев КМП, оценка, которой при осложнениях язвенной болезни ПерфГдя, в свою очередь, может представляться так же непростой $[1,34,38]$ и представлять повод для клинико-экспертных и юридических разбирательств [1, 21].

В Санкт-Петербурге наблюдения внебольничной пневмонии и ОХЗОБП в гибридном варианте по частоте 
Таблица 1. Количество лабораторно подтвержденных случаев заболевания COVID-19 (U07.1) и показатели летальности по России и Санкт-Петербургу 01.08.2020 г.

\begin{tabular}{|l|l|l|l|l|}
\hline $\begin{array}{l}\text { Геополитические } \\
\text { образования }\end{array}$ & $\begin{array}{l}\text { Численность } \\
\text { населения } \\
\text { (по данным Росстата, } \\
\text { млн. чел.) }\end{array}$ & $\begin{array}{l}\text { Число людей } \\
\text { подверженных } \\
\text { заболеванию (чел.) }\end{array}$ & $\begin{array}{l}\text { Численность } \\
\text { контингентов } \\
\text { умерших (чел.) }\end{array}$ & $\begin{array}{l}\text { Показатель } \\
\text { летальности (в \%) }\end{array}$ \\
\hline Россия в целом & 146,748 & 845443 & 14058 & 1,67 \\
\hline Санкт-Петербург & 5,398 & 31622 & 2052 & 6,49 \\
\hline
\end{tabular}

оказываются особенно высокими, так как значительный контингент жителей города составляют люди пожилого и старческого возраста, у которых эти заболевания и в солитарных формах протекают весьма тяжело [16, 37]. Поэтому поиск ответа на вопросы о приоритетной значимости патогенетических компонентов танатогенеза в случаях сочетания заболеваний гастроэнтерологического профиля (в частности осложнений язвенной болезни - ЯБ) и COVID-19-пневмонии представляет особый научно-практический интерес.

\section{Шель исслеАования}

Оценить качество МП на примере разбора случая смерти больного сочетанием язвенной болезни двенадцатиперстной кишки (ДПК), осложненной перфорацией язвы, с COVID-19 патологическим состоянием.

\section{Материалы и метолы}

В 2009 г. в Санкт-Петербурге создана Комиссия по изучению летальных исходов от гриппа и других инфекционных заболеваний (КИЛИГриИнфЗ). К работе в ее составе привлечены ведущие специалисты города в области патологоантомии и клинических профилей медицинской деятельности (в частности - инфекционных болезней), эпидемиологии, организации здравоохранения и др. На 01.08.2020 по данным специалистов КИЛИГриИнф3 констатированы 31622 лабораторно подтвержденных наблюдений НКВИ с кодом диагноза по МКБ-10 U07.1 (лабораторно подтвержденный). C середины июня 2020 г. в Санкт-Петербурге отмечалась тенденция к снижению уровня заболеваемости COVID-19. В ряде случаев тяжелое течение пневмонии, обусловленной вирусом SARS-CoV-2, завершалась летальным исходом. По официальным данным, опубликованным на федеральном портале Стопкоронавирус.РФ, показатель частоты случаев смерти жителей России от пневмонии, вызванной коронавирусом, составил 1,67\% - 14058 чел. В Санкт-Петербурге в это время показатель летальности среди данного контингента больных превышал аналогичный в среднем по РФ почти в 4 раза (2052 чел.), составив $1,67 \%$ (табл. 1).

Тела людей, умерших от инфекционных заболеваний, подвергаются аутопсии, что регламентировано федеральным законом № 323 «Об охране здоровья». В период эпидемического распространения новой коронавирусной инфекции на территории Санкт-Петербурга с марта по август 2020 г. специалистами КИЛИГриИнфЗ проведены 803 разбора по поводу оценки качества оказания медицинской помощи (МП) больным, умерших при констатации факта их инфицированности COVID-19.

Изыскания осуществлялись на основании сведений о результатах клинического обследования пациентов, а также данных тестов лабораторной диагностики и специальных инструментальных технологий.

Из числа случаев коллегиального обсуждения случаев смерти отобраны данные о 60 наблюдениях заболеваний по профилю «хирургия». Среди них углублённому разбору подвергнуты случай оказания МП жителю СПб, умершему при перфорации язвы ДПК на фоне верификации входе его обследования и лечения состояния новой короновирусной инфекции. Данное клиническое наблюдение и приводится в качестве примера сложности интерпретации данных оценки качества медицинской помощи (КМП) при остром животе (ОЖ) в случаях констатации состояния COVID -19 (на модели перфорации дуоденальной язвы).

\section{К^иническое наблюАение}

Больной Б., 35 лет, житель Санкт-Петербурга (СПб) в течение многих лет, наблюдавшийся по поводу хронической язвы ДПК, два дня отмечал знакомые ему признаки обострения ЯБ. Лечился самостоятельно, принимая известные медикаменты, используемые им ранее. 04.04.2020 г. стал отмечать необычные интенсивные боли по всему животу, что сочеталось с выраженной общей слабостью. 
В 19 ч. 18 мин. 04.04.2020 г. специалистами скорой медицинской помощи (СМП) доставлен в один из многопрофильных стационаров города. Диагноз направления учреждения: перитонит.

В стационаре обследован и в крайне тяжелом состоянии госпитализирован, минуя этап приемного покоя, в отделение анестезиологии и реанимации. В связи с тяжестью состояния больной в продуктивный контакт с медицинскими работниками не вступал. По гримасе отмечалась болевая реакция при пальпации во всех отделах живота, спонтанно происходила рвота. Констатировалась выраженная общая слабость. Данные эпиданамнеза - отрицательные. Показатели гемодинамики удерживались на нестабильных цифрах (АД 90/5085/50 мм.рт.ст.). При исследовании живота отмечалось его умеренное вздутие. При перкуссии - тимпанит. Положительные симптомы раздражения брюшины.

Диагноз пациента сформулированный при поступлении: обострение язвенной болезни ДПК, осложнение перфорацией. После проведения краткосрочных мероприятий по стабилизации состояния 04.04.2020 г. пациент, в экстренном порядке доставлен в операционную. Проведена диагностическая лапароскопия, в ходе которой выявлена язва ДПК, разлитой фибринозно-гнойный перитонит. Осуществлена конверсия доступа (лапаротомия). Выполнено ушивание перфоративной язвы ДПК с последующей санацией и дренированием брюшной полости.

В послеоперационном периоде при пребывании пациента на отделении анестезиологии и реанимации его состояние клинически оставалось крайне тяжелым. Больному в первые сутки госпитализации комиссионно назначены препараты, рекомендованные Минздравом.

Результы дополнительных методов обследования: в показателях анализа крови - нормоцитоз, нейтрофилёз 88\%. На обзорных рентгенограммах грудной клетки от 04.04.2020 г. (в прямой проекции, в горизонтально укладке) в проекции язычковых сегментов левого легкого определялось отчётливое снижение пневматизации за счет инфильтрации. Справа рентгенологически очаговых и инфильтративных изменений выявлено не было. Корни легких: слева - малоструктурный, инфильтрирован. Таким образом, по данным рентген исследования, констатирована: левосторонняя пневмония в проекции язычковых сегментов. Вместе с тем, при аускультации лёгких во время клинического обследования больного отчетливо выслушивались множественные как сухие, так и влажные хрипы. В течение почти суток после операции крайне тяжелое состояние больного сохранялось, нарастали явления полиорганной недостаточности. Осуществлялся весь комплекс лечебно-диагностических мероприятий, предусмотренный регламентирующими документами.

05.04.2020 в 164. 45мин. констатировано состояние клинической смерти пациента. Реанимационные мероприятия, проведённые на отделении анестезиологии и реанимации оказались неэффективными, в 17ч.15 мин. 05.04.2020 г. зафиксировано состояние биологической смерти пациента.

\section{Заключительный клинический диагноз:}

Основной: язва ДПК, осложненная перфорацией (лапаротомия от 04.04.2020 г.); подозрение на новую короновирусную инфекцию Covid-19, тяжелая форма, внебольничная двусторонняя пневмония, острая дыхательная недостаточность.

Сопутствующие заболевания: алкогольный гепатит.

Осложнения патологических процессов: распространенный гнойный перитонит, терминальная фаза; тяжелый абдоминальный сепсис; полиорганная недостаточность; инфекционно-токсический шок.

Согласно гистологическим исследованиям по материалам аутопсии (16.04.2020 г.) тела пациента:

Легкие: резкое полнокровие сосудов, множественные кровоизлияния. В части альвеол содержаться нейтрофильные лейкоциты, серозно-фибринозный экссудат, альвеолоциты и макрофаги с незначительно увеличенными ядрами; гиалиновые мембраны видны в единичных альвеолах; трахея не представлена.

Миокард: неравномерная гипертрофия кардиомиоцитов в сочетании с атрофированными кардиомиоцитами; периваскулярный склероз и липоматоз; резко выраженное полнокровии; печень с выраженными очаговыми холестазами, полнокровна.

Брюшина в зоне ушитого язвенного дефекта стенки ДПК с явлениями фибринозно-гнойного воспаления. Лейкоцитарная инфильтрация распространяется на брыжейку. Двенадцатиперстная кишка с выраженным склерозом, очагами некроза, кровоизлиянием, лейкоцитарной инфильтрацией. В просвете мелких сосудов тромбы. В печени, почках, селезенке, головном мозге признаки резкого полнокровия.

Патологоанатомический диагноз окончательно сформулирован:

Основное заболевание: хроническая язва передней стенки луковицы ДПК с прободением (лапарото- 
мия - ушивание язвы); новая коронавирусная инфекция COVID-19 (результаты ПЦP SARS-CoV-2 посмертно); двусторонняя вирусно-бактериальная пневмония.

Фоновое заболевание: хроническая алкогольная интоксикация (алкогольная кардиомиопатия).

Осложнение патологических процессов: фибринозно-гнойный перитонит.

В ходе работы по экспертному разбору случая оказания МП больному Б. возник ряд вопросов. Прежде всего особые трудности интерпретации данных наблюдения испытывались из-за недостаточности информации, которую можно получить только в ходе комплексной оценки КМП на всех этапах её оказания. Последнее констатировалось даже, что на фоне, казалось бы всестороннего изучения и заключений рецензентов, пошагово проследивших объем МП, оказанной пациенту на этапах её предоставления. Недостаточность сведений о полноте оказания МП явно ощущалась при её оценке на догоспитальном этапе. Последнее обстоятельство затрудняло обоснованную формулировку клинико-экспертных выводов разбора.

Очевидно, что с позиции анализа дефектов хирургической деятельности, исход заболевания должен рассматриваться также и с учетом мультидисциплинарных подходов в экстренной медицине, как на госпитальном так и догоспитальных этапах её предоставления. При оказании МП больному Б., определенно усматриваются погрешности, обусловленные как недостатками лечебно-диагностического процесса, так и дефектами в его организации. В частности, обращает на себя внимание отсутствие упоминаний в медицинской карте клинического случая данных о катаральном синдроме у пациента со стороны верхних дыхательных путей (ни в жалобах, ни в показателях объективного обследования) при доминирующей картине перитонита. В представленных медицинских документах отсутствовали сведения о заборе материалов (мазков) на SARS-CoV-2 при жизни пациента, о назначении противовирусных препаратов, а так же о представленных результатах анализов на SARS-CoV-2, выполненных посмертно.

Вместе с тем заключение КИлИГриИнф3: мужчина 35 лет умер от интоксикации, обусловленной сочетанием фибринозно-гнойного перитонита и новой коронавирусной инфекцией COVID-19, осложненной вирусно-бактериальной пневмонией, на фоне которой по экстренным показаниям проведено ушивание язвы ДПК.

По мнению КИЛИГриИнфЗ основным заболеванием следует считать язвенную болезнь ДПК (хроническую её форму), осложненную перфорацией язвы и перитонитом.

Случай по мнению членов КИЛИГриИнфЗ не должен регистрироваться «как смерть от COVID-19».

\section{Обсужление}

Несомненно, что формулировка диагноза, от которого во многом зависит вердикт в отношении генеза заболевания, оказавшегося причиной смерти, в основном определяется на основании заключения морфологического (патологоанатомического) исследования. Главная составляющая работы патологоанатомов - выявление причины летального исхода. Патоморфологи устанавливают характер патологического процесса (в представленном случае - острый/хронический, с градацией стадии течения процесса и с установлением причинно-следственной связи осложнения и летального исхода). Патологоанатомы также свидетельствуют о том, что патологическое состояние, обнаруживаемое в легких, представляет собой не эксклюзивный воспалительный процесс или COVID-19, а казалось бы банальная язвенная болезнь может оказаться другой патологической сущностью. Современные методы морфологических исследований позволяют специалистам выработать суждение о прогнозе течения и исхода заболевания, а используя молекулярно-генетические методики,определять рациональность избранного вида таргетной терапии. При этом учитывается вся известная (порой,объемная) информация о случае, полученная участниками лечебно-диагностического процесса в результате клинических, лабораторных и других специальных исследований. У пациентов может констатироваться несколько заболеваний. Из множества верифицированных патологических состояний специалистам необходимо выявлять основное, оказывающееся непосредственной причиной смерти. Экспертами Всемирной организацией здравоохранения (ВО3) 16.04.2020 г. разработаны методические указания об установлении причинной последовательности, обусловливающий смертельный исход при COVID-19. При анализе данных о конкретных случаях болезни эта последовательность должна четко прослеживаться, начиная от заболевания коронавирусной инфекцией (как от первопричины, приведшей к смерти), до состояния, непосредственно обусловившего смерть пациентов.

Из медицинских организаций в КИЛИГриИнфЗ представляются медицинские карты, протоколы патологоанатомических исследований и гистологические препараты. Анализ этих данных позволяет максимально объективно установить причину смерти и, таким образом, составить заключение с обоснованным уровнем осмысления [11, 19, 28]. 
На вопросы, касающееся механизма смерти, как правило, определенно уже можно ответить по завершению аутопсии. Однако бывает и так, что данные о результатах вскрытия умершего пациента оказываются недостаточными, что порождает необходимость проведения серии исследований по изучению деталей микроскопических изменений в тканях с целью определения значения в танатогенезе структурных процессов, составляющих основу нарушений функций систем организма.

По данным вскрытия можно выявить пневмонию, что отражается в медицинском свидетельстве о смерти. Однако без дополнительных специальных методик исследования однозначно судить об этиологии изменений в легких на основании аутопсии не представляется возможным. В таких случаях исключение составляют наблюдения, когда до смерти больного осуществлена лабораторная верификация вируса SARS-CoV-2 Очевидно, что на этапе сугубо патологоанатомического исследования статистические данные не всегда оказываются полными. На специальные лабораторные и морфологические изыскания отводится порядка 7-10 дней, после чего посмертный диагноз становится конкретным, а статистические данные могут считаться достоверными.

В период пика пандемии COVID-19 в 2020 г. в Санкт-Петербурге членам КИЛИГриИнфЗ не удалось в исчерпывающем масштабе оперативно выполнить весь объем поручений по оценке качества оказания МП в случаях инфицирования населения коронавирусом. Поэтому в настоящее время статистические данные формируются на основании предварительных медицинских свидетельств о смерти, которые необходимо будет скорректировать в последующем к периоду годовой отчетности [33].

Очевидно, что пациенты умирают не только от COVID-19, но и от заболеваний другого генеза. В таких наблюдениях коронавирусная инфекция является сопутствующим заболеванием и не входит в статистические отчеты медицинских организаций. Возможное влияние вируса SARS-CoV-2 на течение и исход основного заболевания окончательно еще не известно и это предстоит изучать в будущем.

В случае летального исхода, сведения о котором изложены в данной публикации, диагноз новой коронавирусной инфекции был предварительно установлен клинически и подтвержден прижизненно. Больному в первые сутки госпитализации комиссионно с оформлением ДИС назначены препараты, рекомендованные Минздравом.

Имевшаяся тяжелая соматическая интеркуррентная патология, несомненно, оказала значимое влияние на исход заболевания.
Результаты исследования, проведенного, в отношении случая заболевания и смерти жителя Санкт-Петербурга, инфицированного SARS-CoV-2 и наблюдаемого по поводу язвенной болезни ДПК, позволяют заключить, что основную роль в танатогенезе занимает тяжелое течение пневмонии, обусловленной коронавирусом. Однако, и осложнения язвенной болезни (в представленном случае - перфорация язвы ДПК) могут оказываться основной причиной смерти. Летальные исходы от COVID-19 чаще всего возникают у лиц пожилого и старческого возраста с выраженной сопутствующей патологией. В этом плане случаи язвенной болезни не оказываются исключением. В последнее время, их частота нарастает по причине медикаментозного генеза т.к. больные старшей возрастной группы, с профилактической целью (порой,- мало контролируемо) масштабно принимают тромболитические средства, обладающие побочными ульцерогенными свойствами.

Для получения окончательных данных по случаю необходимо максимально использовать возможности проведения лабораторных тестов на верификацию вируса SARS-CoV-2, а также разрабатывать и внедрять в алгоритмы диагностики этого патологического состояния тест-системы лучшего качества с более высокими показателями чувствительности и специфичности исследований.

\section{Зак^ючение}

Однозначно ответить на многие вопросы при оценке КМП в обсуждаемом наблюдении, не представляется возможным. Экспертиза, как правило, проводится на основании изучения медицинских документов. Без общения со специалистами, принимавшими непосредственное участие в обследовании и лечении пациента, детали лечебно-диагностического процесса могут быть отражены не полностью, а предоставленные данные, порой, оказываются противоречивыми. Именно по этой причине оценку КМП целесообразно проводить коллегиально с обсуждением клинического случая в кругу профессионального сообщества. На основании заключений целевых экспертиз КМП можно выстраивать оптимальный формат разбора случая. Сведения о наблюдении, представленном в данной публикации, подтверждают мнение о сложности оценки (с организационно-управленческих позиции) причинно-следственной связи течения заболевания, обусловливающего летальный исход. Очевидна необходимость коллегиального обсуждения профессиональным сообществом тяжелых / не стандартных случаев заболеваний ОХЗОБП. Однако нельзя не признать, что заседания клинико-экспертной комиссии не должны напоминать разбирательства в судах или в подразделениях следственных органов. 


\section{ЛИТЕРАТУРА}

1. Бастрыкин А. И. Криминалистическая характеристика преступлений, связанных с ненадлежащим оказанием медицинской помощи и медицинских услуг [электронный ресурс] / А. И. Бастрыкин.—Режим доступа: http: // www.moniiag.ru / wp — content/.

2. Беглов А. Д. Мы обязаны готовиться к самому сложному сценарию [электронный ресурс] URL: https://www.fontanka.ru/2020/07/13/69364561/ (дата 06ращения 08.08.2020).

3. Беркинов У. Б. Некоторые аспекты диагностики и лечения прободных дуоденальных язв / У. Б. Беркинов, М. Ш. Хакимов, У. И. Маткулиев и др. // Вестник экстренной медицины. - 2018. — № 4 (11). - С. 26-32.

4. Борисов А. Е. Проблемы острого живота: (ошибки, осложнения, летальность) /А.Е. Борисов, К. Н. Мовчан, В. Ф. Озеров и др. Изд. 2-е, доп.- СПб.: издательский дом СПБ МАПО, 2004.- 174 с.

5. Васильев В. А. Глава Дагестана заявил о «переломе» ситуации с коронавирусом [электронный ресурc] URL: https://www.rbc.ru/society/27/05/2020/5ecd96 8e9a794769d2d1d777 (дата обращения 02.08.2020).

6. Вачев А. Н. Определение агрессивности течения перитонита (пилотное исследование) / А. Н. Вачев, В. К. Корытцев, В. Ю. Щербатенко и др. // Хирургия. Журнал им. Н. И. Пирогова. — 2018. — № 11- С. 31-34. https://doi.org/10.17116/hirurgia201811131.

7. Витько А. В. Минздрав Хабаровского края заявил о росте заболеваемости коронавирусом [электронный ресурc] URL: https://www.interfax.ru/russia/718035 (дата обращения 09.08.2020).

8. Ганцев Ш.Х. Рак во время пандемии коронавирусной инфекции COVID-19 / Ш.Х. Ганцев, Р. А. Рустамханов // Медицинский вестник Башкортостана.2020. 一 Том 15, № 3 (87). - С. 51-58.

9. Гарелик П. В. Перфоративные гастродуоденальные язвы: взгляд на проблему выбора метода оперативного лечения / П. В. Гарелик, 0. И. Дубровщик, И. С. Довнар и др. // Новости Хирургии.— 2014.—№ 3 (22).—С. 321-325.

10. Голикова Т. А. Голикова рассказала о темпах прироста случаев COVID-19. Известия [электронный ресурc] URL: https://iz.ru/1041481/2020-07-29/golikovarasskazala-o-tempakh-prirosta-sluchaev-covid-19 (дата обращения 02.08.2020).

11. Голикова Т. А. Голикова оценила летальность коронавируса в России в менее чем 2,5\%. [элетронный ресурc] URL: https://www.interfax.ru/russia/719443 (дата обращения 02.08.2020)

12. Гриневич В. Б. Особенности ведения больных с гастроэнтерологической патологией в условиях пандемии COVID-19. /B.Б. Гриневич, Ю. А. Кравчук, Е. И. Ткаченко и др. // Экспериментальная и клиническая гастроэнтерология. — 2020 176(4). doi:10.31146/1682-8658-ecg-176-4.

13. Каприн А. Д. Влияние пандемии COVID-19 на онкологическую практику / А. Д. Каприн, Е. В. Гамеева, А. А. Поляков, А. Л. Корниецкая, Н. А. Рубцова, А. А. Феденко // Сибирский онкологический журнал. — 2020 19(3) - C. 5-22. — doi: 10.21294/1814-4861-2020-19-3-5-22.

14. Кондратьев В. И. Власти Кубани усилят контроль за соблюдением правил Роспотребнадзора [электронный pecypc] URL: https://www.gazeta.ru/social/ news/2020/07/22/n_14704963.shtml (дата обращения 09.08.2020).

15. Кочетков А. В. Качество оказания хирургической помощи населению Санкт-Петербурга в 2015 году//А.В. Кочетков// Ежегодная конференция хирургов Северо-Запада «Актуальные воросы хирургии».-СПб.:[Би], 2015.—С. 13-14.

16. Лисовец Д. Г. Каким было первое полугодие эпохи COVID-19 в Петербурге / Д. Г. Лисовец // Петербургский дневник. Газета. — 07.07.2020.—C. 8-9.

17. Малхасян В.А.Оказание стационарной помощи пациентам урологического профиля в условиях пандемии коронаровирусной инфекции COVID-19. / В. А. Малхасян, Г. Р. Касян, Л. А. Ходырева, К. Б. Колонтарев, А. В. Говоров, А. О. Васильев, Д. Ю. Пушкарь // Экспериментальная и клиническая урология.2020 (1):4-11. doi: 10.29188/2222-8543-2020-12-1-4.

18. Медведев Д. А. Медведев не исключил возникновения новых волн коронавируса. Известия. [электронный ресурc] URL: https://iz.ru/1035286/2020-07-14/ medvedev-ne-iskliuchil-vozniknoveniia-novykh-voln-koronavirusa (дата обращения 25.08.2020).

19. Международные методические рекомендации по удостоверению и кодированию covid-19 в качестве причины смерти основаны на международной статистической классификации болезней и проблем, связанных со здоровьем (методические рекомендации от 20.04.2020 (В03).

20. Мельник A.A. COVID-19 и сопутствующие заболевания / А. А. Мельник //Новости медицины и фармации. Газета. Киев. — 2020. — № 6 (724), [элетронный pecypc] URL: http://www.mif-ua.com/archive/article/49424 (дата обращения 29.08.2020).

21. Мовчан К.Н. Результаты эффективности обследования и лечения пациентов с патологией хирургического профиля по данным экспертизы качества медицинской помощи// К. Н. Мовчан, В. В. Ерошкин, А. Д. Тарасов и др./ Вестник Российской Военно-медицинской академии. 一 2016. - № 4 (56). C. 164-169.

22. Мусабаев Н. Х. Опыт технологий при перфоративных язвах желудка и двенадцатиперстной кишки / Н. Х. Мусабаев, А. Е. Адилова, А. Б. Мусилимова и др. // Вестник КазНМУ.— 2016. — № 4.—C. 192-196.

23. Парфенов В. Е. Информационные материалы по неотложной хирургической помощи при острых хирургических заболеваниях органов брюшной полости в Санкт-Петербурге за 2017 год / под ред. проф. В. Е. Парфенова.—СПб.: фирма «Стикс», 2018.-24 с.

24. Попова А. Ю. Заседание Координационного совета при Правительстве по борьбе с распространением новой коронавирусной инфекции на территории Российской Федерации 15.07.2020 [элетронный ресурc] URL: http://government.ru/news/40023/ (дата обращения 01.08.2020)

25. Попова А. Ю. Серьезного снижения заболеваемости COVID-19 нет в десяти регионах [элетронный ресурc] URL: https://ria.ru/20200618/1573150795.html (дата обращения 01.08.2020).

26. Профилактика, диагностика и лечение новой коронавирусной инфекции (COVID-19) у онкологических больных / Серия изданий «Беседы о Болезни» под редакцией академика РАН Каприна А. Д. Москва, — 2020. - 18 c. 
27. Пушкарь Д.Ю. COVID-19: Влияние на урологическую службу Российской Федерации / Д. Ю. Пушкарь, Г. Р. Касян, В. А. Малхасян, Н. А. Сазонова, И. А. Шадеркин, В. А. Шадеркина // Экспериментальная и клиническая урология. — 2020; (2). — C. 13-17. doi: 10.29188/2222-8543-2020-12-2-13-17.

28. Рыбакова М. Г. Не предполагали, как далеко зайдет коронавирус / М. Г. Рыбакова // Петербургский дневник. Газета.— 04.08.2020.—C. 8-9.

29. Сивков А. В. Мочеполовая система и COVID-19: некоторые аспекты / А. В. Сивков, А. В. Корякин, А. А. Синягин, О. И. Аполихин, А. Д. Каприн // Экспериментальная и клиническая урология. — 2020; (2). - С. 18-23. doi: 10.29188/2222-8543-2020-12-2-18-23.

30. Собянин С. С. Коронавирус в Москве не отступает [электронный ресурc] URL: https://www.interfax.ru/moscow/722887 (дата 0бращения 29.08.2020).

31. Стопкоронавирус. РФ. Оперативные данные по состоянию на 05 августа 2020 г. [электронный ресурс] URL: стопкоронавирус.рф (дата обращения 06.08.2020).

32. Суковатых Б. С. Отдаленные результаты хирургического лечения язвенной болезни желудка и двенадцатиперстной кишки, осложненной перфорацией / Б. С. Суковатых, И. И. Гуреев, Ю. П. Новомлинец и др. // Курский научно-практический вестник «Человек и его здоровье».— 2017—№3.—C. 30-36.

33. Титова 0.Н. В Петербурге комиссия по летальным исходам признает «ковидными» половину рассмотренных смертей [электронный ресурс] URL: https:// www.fontanka.ru/2020/05/23/69275494/ (дата обращения 21.07.2020).

34. Чавпецов В.Ф. Автоматизированная технология экспертизы качества медицинской помощи: структура, результаты и перспективы применения: информационные материалы / В. Ф. Чавпецов, С. М. Михайлов, М. А. Карачевцева.—СПб.: [Б.и.], 2007.— 65 с.

35. Чучалин А. Г. Эпидемия коронавируса должна избавить наше общество от беспечности [элетронный ресурс] URL: https://interaffairs.ru/news/show/26035 (дата обращения 25.07.2020).

36. Шамов В. Н. Острые диффузные перитониты и их лечение // Новый хирургический архив. - 1937. - С. 10-30.

37. Шляхто Е. В. Увеличение числа заболевших коронавирусом в Петербурге связано с улучшением выявляемости [элетронный pecypc] URL: https://topspb. tv/news/2020/07/10/evgenij-shlyahto-uvelichenie-chisla-zabolevshih-koronavirusom-v-peterburge-svyazano-s-uluchsheniem-vyyavlyaemosti/ (дата 0бращения 04.08.2020).

38. Яблонский П.К., Кабушка Я.С., Орлов Г. М. и др. Возможности использования элементов управленческого учета при оценке эффективности деятельности хирургической службы крупного города (на примере Санкт-Петербурга) // Вестник СПбГУ. Серия 11. Медицина. 2016. Bып. 4. C. 62-75. https://doi.org/ 10.21638/11701/spbu11.2016.406.

39. AL-Shamsi H.0., Alhazzani W., Alhuraiji A. et al. A Practical Approach to the Management of Cancer PatientsDuring the Novel Coronavirus Disease 2019 (COVID-19) Pandemic: An International Collaborative Group // The oncologist. — 2020. — Vol. 25(6). - P. 3-9.

40. American Society of Clinical Oncology. Руководство по оказанию медицинской помощи онкологическим больным во время пандемии COVID-19 [электронный ресурс] URL: https:/www.asco.org/sites/new-www.asco.org/files/content-files/international-programs/documents/2020-ASC0-Guide-Cancer-COVID19Russian.pdf (дата обращения 16.07.2020).

41. Apicella M., Campopiano M. C., Mantuano M. rt al. COVID-19 in people with diabetes: understanding the reasons for worse outcomes // Lancet. — 2020.—Vol.8 (9), - P. 782-792.

42. Buck D. L. Surgical delay is a critical determinant of survival in perforated peptic ulcer / D. L. Buck, M. Vester-Andersen and M. H. Møller // British Journal of Surgery.-2013.—P. 1045-1049.

43. Cheng Y., Luo R., Wang K. et al. Kidney disease is associated with in-hospital death of patients with COVID-19. Kidney International. — 2020. Vol. 97(5). — P. 829-838.

44. Delay in Source Control in Perforated Peptic Ulcer Leads to 6\% Increased Risk of Death Per Hour: A Nationwide Cohort Study / H. Boyd-Carson, B. Doleman, D. Cromwell et all. // World Journal of Surgery. — 2019. https://doi.org/10.1007/s00268-019-05254-x.

45. EAU Robotic Urology Section (ERUS) guidelines during COVID-19 emergency. https://uroweb.org/eau-robotic-urology-section-erus- guidelines-during-covid-19emergency/, accessed on March 29, 2020.

46. Ficarra V, Novara G, AbrateA, Bartoletti R, Crestani A, de Nunzio C, et al. Urology practice during COVID-19 pandemic. Minerva UrolNefrol 2020 Mar 23. doi: 10.23736/ S0393-2249.20.03846-1.

47. Kutikov A., Weinberg D. S., Edelman E. M. A War on Two Fronts: Cancer Care in the Time of COVID-19. Annals of Internal Medicine@. American College of Physicians. 2020.

48. LiZ., Wu M., Guo J. et al. Caution on kidney dysfunctions of 2019-nCoV patients 2020. MedRxiv preprint. Available at: https://doi.org/10.1101/2020.02.08.20021212. Accessed March 14,- 2020.

49. Liang W., Guan W., Chen R. et al. Cancer patients in SARS-CoV-2 infection: a nationwide analysis in China. Lancet Oncol. 2020. 21. 335-337. PMID: 32066541. doi: 10.1016/S1470-2045(20)30096-6.

50. Ning N., Xia SY., Ma B., Li R., DU XH. Application of laparoscopic technique in acute abdomen of gastrointestinal surgery. Zhonghua Wei Chang Wai Ke Za Zhi. 2013 0ct; 16(10). - P. 960-962.

51. Stensland KD, Morgan TM, Moinzadeh A, Lee CT, Briganti A, Catto J, Canes D. Considerations in the triage of urologic surgeries during the COVID-19 pandemic. Eur Urol 2020 in press 2020;77(6):663-666. doi: 10.1016/j.eururo.2020.03.027.

52. Zhou F., Yu T., Du R. et al. Clinical course and risk factors for mortality of adult inpatients with COVID-19 in Wuhan, China: a retrospective cohort study. // Lancet. March 28, 2020.-Vol.395(10229). - P. 1054-1062.

( ) Мовчан Константин Николаевич ( movchank@miac.zdrav.spb.ru ), Татаркин Владислав Владимирович (vlad1k2@yandex.ru ), Дарьина Мария Геннадьевна ( DaryinaM@spbmiac.ru ), Творогов Дмитрий Анатольевич ( tvorogovd@bk.ru ), Чернов Кирилл Евгеньевич, Жарков Александр Вячеславович, Артюшин Борис Сергеевич Повалий Андрей Александрович.

Журнал «Современная наука: актуальные проблемы теории и практики» 